Research Article

\title{
Glycated Hemoglobin Levels in Patients with Decompensated Cirrhosis
}

\author{
Jeffrey Nadelson, ${ }^{1}$ Sanjaya K. Satapathy, ${ }^{2}$ and Satheesh Nair ${ }^{2}$ \\ ${ }^{1}$ Division of Gastroenterology and Hepatology, University of Tennessee Health Sciences Center, Memphis, TN, USA \\ ${ }^{2}$ Methodist Transplant Institute, Division of Surgery, University of Tennessee Health Sciences Center, Memphis, TN, USA \\ Correspondence should be addressed to Satheesh Nair; snair@uthsc.edu
}

Received 20 April 2016; Revised 27 July 2016; Accepted 18 September 2016

Academic Editor: Dario Iafusco

Copyright (C) 2016 Jeffrey Nadelson et al. This is an open access article distributed under the Creative Commons Attribution License, which permits unrestricted use, distribution, and reproduction in any medium, provided the original work is properly cited.

\begin{abstract}
Introduction. Aim of this study is to determine if HbAlc levels are a reliable predictor of glycemic control in patients with decompensated cirrhosis. Methods. 200 unique patients referred for liver transplantation at University of Tennessee/Methodist University Transplant Institute with a HbAlc result were included. Three glucose levels prior to the "measured" Alc (MAlc) were input into an HbAlc calculator from the American Diabetes Association website to determine the "calculated" Alc (CAlc). The differences between MAlc and CAlc levels were computed. Patients were divided into three groups: group A, difference of $<0.5$; group B, 0.51-1.5; and group C, >1.5. Results. 97 (49\%) patients had hemoglobin A1c of less than 5\%. Discordance between calculated and measured HbAlc of $>0.5 \%$ was seen in $47 \%(n=94)$. Higher level of discordance of greater than $>1.5$ was in $12 \%$ of patients $(n=24)$. Hemoglobin was an independent predictor for higher discordance (odds ratio $0.7795 \%$, CI $0.60-0.99$, and $p$ value 0.04 ). HbAlc was an independent predictor of occurrence of HCC (OR 2.69 955, CI 1.38-5.43, and p value 0.008). Conclusion. HbA1c is not a reliable predictor of glycemic control in patients with decompensated cirrhosis, especially in those with severe anemia.
\end{abstract}

\section{Introduction}

Hemoglobin Alc (HbAlc) is the gold standard for the measurement of long-range glycemic control in patients with diabetes mellitus. Many studies have reported diabetes mellitus to be a risk factor in patients with alcoholic liver disease and nonalcoholic fatty liver disease (NAFLD) for the development of fibrosis and fibrosis progression [1-3]. In the United States, $2 \%$ of adult Americans (5.3 million) are infected with hepatitis B or C [4] and an estimated $31 \%$ or more with NAFLD $[5,6]$.

The presence of CLD is associated with significant impairment in glucose homeostasis. Glucose intolerance is seen in up to $80 \%$ of patients with CLD, and frank diabetes is present in $30-60 \%[7,8]$. Depending on its etiology, CLD has a significant impact on hepatic glucose metabolism.

Among patients with CLD, anemia, portal hypertension, hypersplenism, and variceal bleeding can be common complications. These factors can contribute to longer or shorter red blood cell (RBC) survival [9] and can lead to alteration of the HbAlc. Factors such as nutritional anemia can lead to increased $\mathrm{RBC}$ survival and falsely elevated $\mathrm{HbAlc}$ levels, whereas bleeding and hemolysis can lower RBC survival time and falsely lower $\mathrm{HbAlc}$ values.

Very few studies are dedicated to systematically evaluating the accuracy of HbAlc in CLD patients. In a screening of 20,000 measurements of $\mathrm{HbAlc}$, patients with a very low $\mathrm{HbAlc}$ were analyzed further. Of nine abnormally low results, six were the result of cirrhosis, two resulted from hematological neoplasms with anemia, and one was due to hemoglobin $\mathrm{F}$ [10]. In a small case series (15 patients with compensated cirrhosis and 20 patients with chronic hepatitis), $40 \%$ of cirrhotic patients with diabetes had HbAlc levels below reference range for patients without diabetes [11].

Methodist University Hospital Transplant Institute has been systematically screening its liver transplantation candidates for diabetes with $\mathrm{HbAlc}$ levels. Measuring $\mathrm{HbAlc}$ is the gold standard for monitoring blood glucose control in diabetes and can now also be used to diagnose diabetes when its results are $\geq 6.5 \%$ [12].

The study objective is to look at glucose and HbAlc levels in cirrhotic patients and determine if HbAlc levels are a 
reliable predictor of glycemic control in patients who are presented for liver transplantation at Methodist University Hospital Transplant Institute between January 1, 2006, and January 1, 2014.

\section{Methods}

The University of Tennessee Health Sciences Center institutional review board approved this study. The study population included 200 electronic medical records (EMR) of patients who were evaluated for liver transplantation at the Methodist University Hospital Transplant Institute in Memphis, Tennessee, from July 7, 2010, through September 22, 2011. Case selection was restricted to patients who had HbAlc levels in the EMR. Patients who did not have HbAlc levels in the EMR were excluded from the study. Patients were referred for liver transplantation after they were evaluated by a primary care physician or gastroenterologist; the referral was indicated for them based on their clinical presentation and results of laboratory and diagnostic tests such as computed tomography (CT) scans or magnetic resonance imaging (MRI) or Model of End Stage Liver Disease (MELD) scores.

The relevant clinicopathologic information was logged into a Microsoft Access database. We reviewed comprehensive history and physical examination at time of referral to the Transplant Institute. The collected data included patients' demographics, cigarette smoking and alcohol history, past medical history, whether or not they were transplanted, MELD at time of time transplant, liver alone or simultaneous liver-kidney transplant, etiology of liver disease, HbAlc level reported from laboratory, and three glucose levels at time of transplant referral. Three glucose levels prior to the "measured" HbAlc (MA1c) were averaged, logged, and input into an HbAlc calculator from the American Diabetes Association website (http://professional .diabetes.org/diapro/glucose_calc) to determine the "calculated" HbAlc (CA1c). The difference between MA1c and CA1c levels was computed and the patients were divided into three groups: group 1, difference of $<0.5$; group 2, 0.51-1.5; and group $3,>1.5$.

All analyses were performed using the software SPSS (SPSS, Inc., Chicago, Illinois). Data is presented as mean and $\mathrm{SD}$ or median and range. Variables between the three groups were analyzed by one-way ANOVA and Chi-square tests for ordinal and categorical variables. $t$-test was used for continuous variables and $z$ test for comparison of proportions. A $p$ value $<0.05$ was considered statistically significant.

\section{Results}

The medical records of patients who were evaluated for liver transplantation and had HbAlc levels collected at the Methodist University Hospital Transplant Institute in Memphis, Tennessee, from July 7, 2010, through September 22, 2011, were reviewed, yielding a total of 200 cases. The mean age for this cohort was 54 years with a male predominance: $67 \%$ were male. Seventy-nine percent were Caucasian. Fortyfour percent and $39 \%$ of patients had a history of alcohol abuse and smoking history, respectively. Sixty-two patients
(31\%) in this study were diabetics. Of those 62 diabetic patients, $26(42 \%)$ were on insulin.

Of the 200 patients included in this study, 55.5\% (111) underwent liver transplant and of those 111 patients who underwent liver transplant, 10\% (11) underwent simultaneous liver and kidney transplant. Average MELD score at time of transplant was 22. Most common etiology of liver disease in our cohort was hepatitis C virus at $41 \%$ (82), followed by hepatocellular carcinoma (HCC) 23\% (46), alcohol $22 \%$ (44), nonalcoholic steatohepatitis (NASH) 16\% (32), primary sclerosing cholangitis 6\% (12), primary biliary cholangitis $4.5 \%$ (9), and hepatitis B virus $4.5 \%$ (9). The remaining $14 \%$ (28) of patients in this cohort referred to Transplant Institute included patients with cryptogenic cirrhosis, autoimmune hepatitis, alpha-1-antitrypsin deficiency, Wilson's disease, hemochromatosis, polycystic liver disease, cholangiocarcinoma, and neuroendocrine tumor.

The distribution of MAlc and the average glucose levels are depicted in Figure 1 (all patients), Figure 2 (patients without diabetes), and Figure 3 (patients with diabetes). The expected glucose levels for each range of MAlc ( $x$-axis) values were obtained from the following website: http://www .diabeteschart.org/bgcl.html. One can infer from the figure that the MA1c values tend to group towards the lower values and actual average glucose values tend to group towards the higher values. For example, among diabetic patients, 58\% of patients had MA1c $<6$, while $77 \%$ of patients had actual average glucose levels of more than $140 \mathrm{mg} / \mathrm{dL}$. Similarly $88 \%$ of nondiabetic patients had HbAlc $<5.5$, but $38 \%$ had actual average glucose levels of more than $110 \mathrm{mg} / \mathrm{dL}$.

Ninety-seven (49\%) patients had HbAlc of less than 5 followed by $72(36 \%)$ patients with hemoglobin Alc of 5-6 and 21 patients $(11 \%)$ with hemoglobin of more than 7 . The discordance between CA1c and MA1c was further categorized into three groups: group 1, the difference between CA1c and MAlc $<0.5(n=106)$; group 2 , the difference between CAlc and MAlc 0.5-1.5 $(n=70)$; and group 3, the difference between CA1c and MAlc $>1.5(n=24)$. Patients with high discordance were more anemic and had higher incidence of diabetes (Table 1). In a multivariate model including those with high discordance versus those with no discordance, hemoglobin levels were the only independent predictor (odds ratio 0.77 95\% CI $0.60-0.99$; $p$ value 0.04 ).

Among the 200 patients included in the study, 46 patients had HCC.(29 in nondiabetics (29\%) and 17 in diabetics $(27 \%))$. As expected, HCC was most commonly seen in patients with hepatitis $\mathrm{C}$ and NASH. The clinical features of patients with HCC and without HCC are highlighted in Table 2. In the multivariate model independent predictors of HCC were measured by HbAlc (OR 2.69 955, CI 1.38-5.43, and $p$ value 0.008 ) and age (OR $1.07955, \mathrm{CI} 1.02-1.13$, and $p$ value 0.004$)$. Female gender was a negative predictor for HCC (OR $0.2495 \%$, CI $0.94-0.637$, and $p$ value 0.004 ). Presence of diabetes was not predictor for HCC.

To further study the relationship between HbAlc and HCC we studied the 62 patients with diabetes. Seventeen patients $(27 \%)$ had HCC. In a multivariate analysis, HbAlc is an independent predictor of HCC (OR 2.14 95\%, CI 1.23-3.70, and $p$ value 0.007$)$. There is progressive increase in incidence 


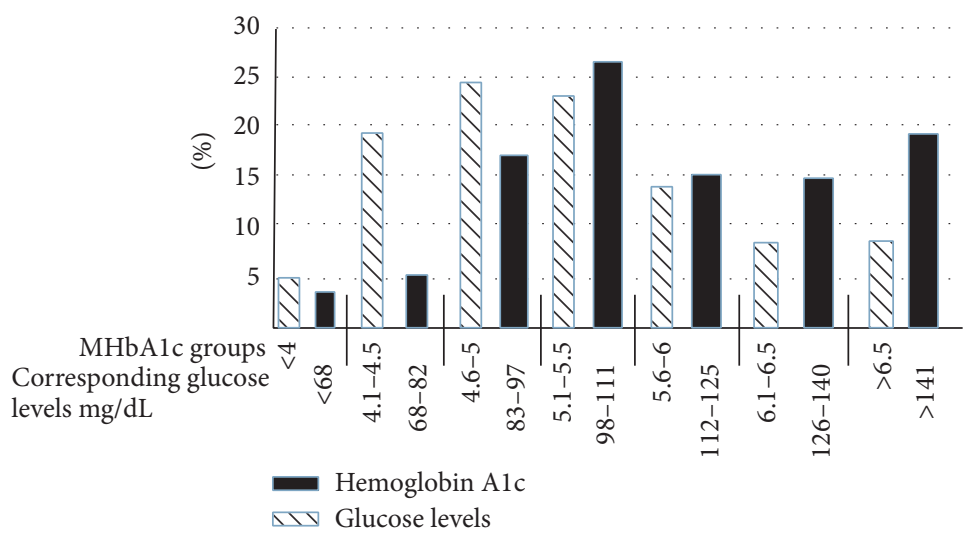

FIgURE 1: Percentage distribution of HbAlc and average glucose levels in 200 patients. The numbers on $x$-axis represent the measured HbAlc groups and the expected glucose levels $(\mathrm{mg} / \mathrm{dL})$ for each group of measured HbAlc.

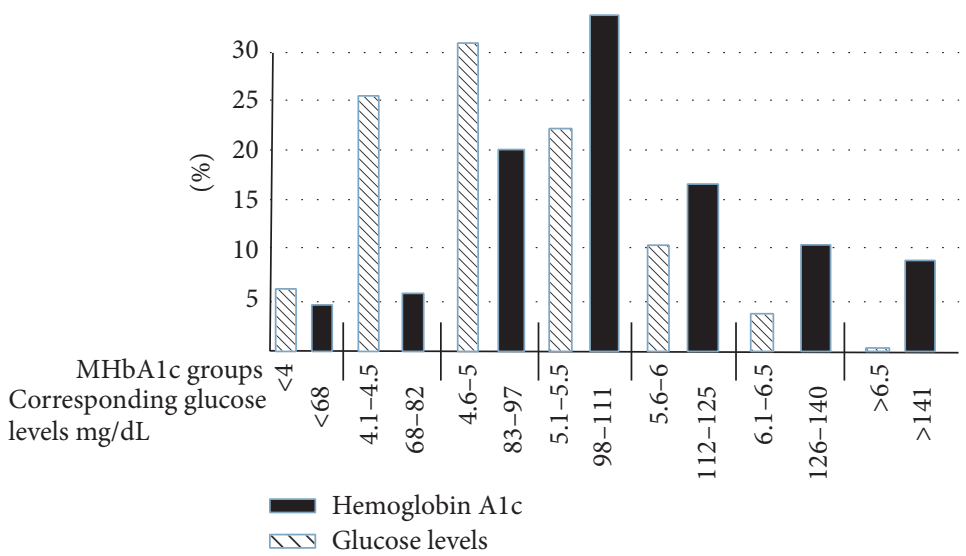

Figure 2: Percentage distribution of HbAlc and average glucose levels in 138 nondiabetic patients. The numbers on $x$-axis represent the measured HbAlc groups and the expected glucose levels $(\mathrm{mg} / \mathrm{dL})$ for each group of measured HbAlc.

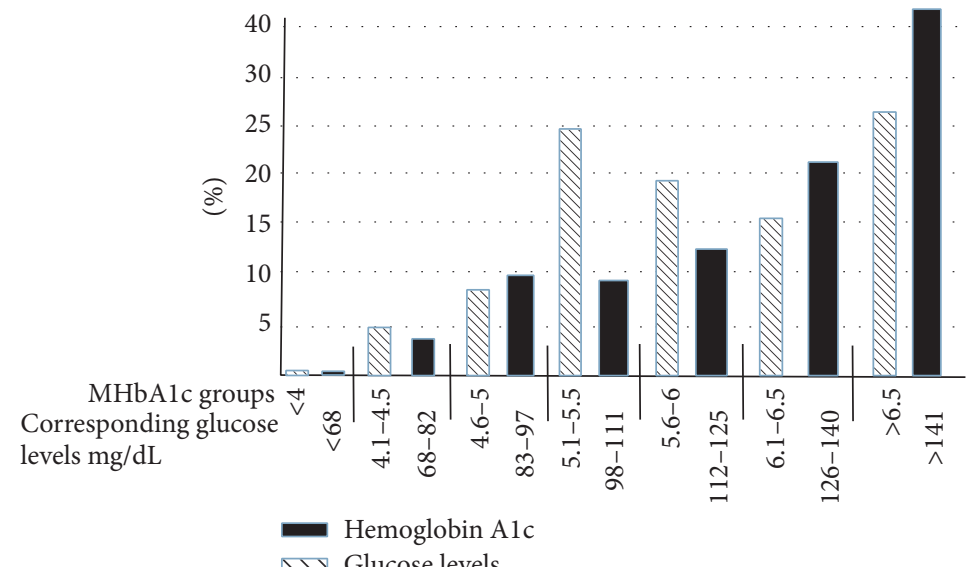

FIGURE 3: Percentage distribution of HbAlc and average glucose levels in 62 diabetic patients. The numbers on $x$-axis represent the measured $\mathrm{HbAlc}$ groups and the expected glucose levels $(\mathrm{mg} / \mathrm{dL})$ for each group of measured HbAlc. 
TABLE 1: The characteristics of the groups based on difference between the calculated and measured hemoglobin Alc.

\begin{tabular}{lccc}
\hline & Group 1 $(n=106)$ & Group 2 $(n=70)$ & Group 3 $(n=24)$ \\
\hline Age & $53 \pm 11$ & $56 \pm 8$ & $52 \pm 10$ \\
Gender (M/F) & $70 / 36$ & $46 / 24$ & $18 / 6$ \\
BMI & $28.1 \pm 5.6$ & $28.6 \pm 6.0$ & $28.6 \pm 5.8$ \\
Etiology of Liver disease (\%) & & & $50 / 17 / 17$ \\
$\quad$ HCV\%/NASH\%/alcohol\% & $40 / 21 / 20$ & $40 / 20 / 14$ & $50 \%$ \\
DM & $26 \%$ & $31 \%$ & $10.9 \pm 2.3^{*}$ \\
Hemoglobin (gm/dL) & $12.2 \pm 2.3$ & $11.6 \pm 1.9$ & $37 \%{ }^{*}$ \\
Hemoglobin $<10$ & $20 \%$ & $19 \%$ & $32.3 \pm 7.0^{*}$ \\
Hematocrit & $36 \pm 6.8$ & $34.5 \pm 5.6$ & $1.23 \pm 0.75$ \\
S. creatinine (mg/dL) & $1.23 \pm 1.3$ & $1.27 \pm 1.08$ & $2.9 \pm 0.7$ \\
Albumin (gm/dL) & $3.0 \pm 0.7$ & $2.9 \pm 0.8$ & $104 \pm 71$ \\
Platelets & $120 \pm 95$ & $122 \pm 86$ & $6.0 \pm 1.8^{*}$ \\
HBAlc (measured) & $5.1 \pm 0.7$ & $5.1 \pm 1.1$ & $8.6 \pm 2.6^{*}$ \\
Calculated HBAlc\# & $5.2 \pm 0.6$ & $6.0 \pm 1.13$ & \\
\hline
\end{tabular}

Group 1: the difference between calculated and measured Alc $<1.0$, group 2: the difference between calculated and measured Alc 0.5-1.0, group 3: the difference between calculated and measured Alc $>1.5$.

${ }^{*}$ Indicate a $p$ value $<0.05$.

TABLE 2: Patients with HCC and patients without HCC.

\begin{tabular}{lccc}
\hline & No HCC $(n=154)$ & with HCC $(n=46)$ & $p$ value \\
\hline Age & $52 \pm 10$ & $58 \pm 6$ & 0.0001 \\
Gender (\% males) & $61 \%$ & $84 \%$ & 0.0001 \\
BMI & $28 \pm 5.5$ & $28 \pm 5.9$ & NS \\
Etiology of liver disease & & & \\
$\quad$ HCV/NASH/alcohol & $36 / 20 / 20$ & $59 / 24 / 11$ & 0.001 \\
DM & $26 \%$ & $43 \%$ & 0.01 \\
Hemoglobin & $11.5 \pm 2.1$ & $13.0 \pm 2.1$ & 0.001 \\
Creatinine & $1.35 \pm 1.3$ & $0.9 \pm 0.3$ & 0.029 \\
Albumin & $2.9 \pm 0.7$ & $3.1 \pm 0.8$ & NS \\
Platelets & $124 \pm 98$ & $102 \pm 70$ & NS \\
HBAlc (measured) & $5.1 \pm 0.8$ & $5.4 \pm 1.6$ & 0.002 \\
\hline
\end{tabular}

of HCC with HbAlc levels. Lowest incidence of HCC, 13.4\%, is seen in patients with $\mathrm{HbAlc}$ being less than 5 , followed by $28 \%$ for HbAlc levels of 5-6, 38\% for patients with HbAlc levels of $6-7$, and $50 \%$ for patients with HbAlc greater than 7 ( $p$ value 0.0001$)$.

\section{Discussion}

Cirrhosis and advanced liver disease have been associated with an increased risk for hyperglycemia and diabetes mellitus. The diagnostic yield of common tests used to define diabetes in the general population differs from those with liver disease. HbAlc is a reliable test to assess chronic glycemia and recommended both for the diagnosis and monitoring of diabetes mellitus; however, HbAlc is neither accurate nor reliable in patients with cirrhosis [11]. Various kinds of anemia are common in liver disease, such as macrocytic anemia [13]. Liver cirrhosis promotes glucose intolerance and diabetes through various mechanisms including insulin resistance and impaired insulin secretion. Sixty to $80 \%$ of patients with liver disease have glucose intolerance and $10-15 \%$ eventually develop overt diabetes [14].

Patients with cirrhosis are frequently anemic and therefore $\mathrm{HbAlc}$ measurements may not provide accurate measure of glycemic control as shown in our analysis. Most common causes of anemia in patients with liver disease are chronic gastrointestinal (GI) blood loss from portal hypertension [15-17] and aplastic anemia secondary to viral hepatitis [18-21]. In addition, antiviral therapy, especially ribavirin, for hepatitis C [22-24] or immunosuppressive agents used to treat autoimmune liver diseases can lead to anemia. In patients with alcoholic liver disease, several factors such as nutritional deficiency, malabsorption, and direct toxic effect of alcohol on bone marrow can cause anemia [25-27].

Hypersplenism secondary to portal hypertension is another important mechanism of anemia in patients with chronic liver disease. Hypersplenism is associated with pancytopenia and is almost universally present in patients with 
cirrhosis. Hemolytic anemia occurs because of intrasplenic destruction of erythrocytes [28]. Any condition that shortens erythrocyte survival or decreases mean erythrocyte age (e.g., recovery from acute blood loss, hemolytic anemia) will falsely lower HbAlc test results [29]. HbAlc results must be interpreted with caution given the pathological processes, including anemia, increased red cell turnover, and transfusion requirements, that adversely impact $\mathrm{HbAlc}$ as a marker of long-term glycemic control.

Our cohorts were decompensated cirrhotic patients needing transplant. The etiology of anemia is most likely related to hypersplenism or hemolysis associated end stage liver disease or chronic GI blood loss from portal hypertensive gastropathy. Since etiology of anemia in patients with decompensated cirrhosis is multifactorial, our retrospective study could not analyze the effects of different types of anemia on HbAlc levels in these patients.

Cirrhosis and advanced liver disease have been associated with an increased risk for hyperglycemia and type 2 diabetes mellitus (T2DM). The diagnostic yield of common tests used to define diabetes and insulin resistance in the general population differs significantly from the one observed in patients with liver disease. HbAlc is a reliable test to assess chronic glycemia and recommended both for the diagnosis and monitoring of T2DM; however, HbAlc is neither accurate nor reliable in patients with cirrhosis. A validation study has not been performed to define its true usefulness in the setting of cirrhosis.

The results of our analysis suggest there is discordance in HbAlc measurements in patients with decompensated cirrhosis. The patients with the highest difference between HbAlc levels had significantly more anemia. This study indicates that HbAlc levels are not a reliable predictor of glycemic control in patients with decompensated cirrhosis, especially in those with severe anemia. To date there are limited numbers of studies dedicated to systematically evaluating the accuracy of HbAlc levels in cirrhotic patients. It is critical for providers and patients to have evidence-based data to guide their management strategies to optimize individualized care. Therefore, we conducted a comprehensive review of 200 unique patients referred to the Methodist University Hospital Transplant Institute with at least one HbAlc level to help provide insight and help guide physicians decision-making in this uncertain area.

Although diabetes is a major public health problem and the fifth leading cause of death in the United States [30] it is less known to be associated with increased risks of developing HCC [31-33]. Although such an association could be related to the underlying chronic liver diseases that preceded the development of HCC [34-37], there are several lines of evidence suggesting that diabetes is in fact an independent risk factor for HCC development [37-39]. There is also evidence reporting that findings of $\mathrm{HCC}$ recurrence after liver resection and transplantation are seen among patients with diabetes $[40,41]$. It is interesting that in our data set diabetes was not independent predictor of $\mathrm{HCC}$, while $\mathrm{HbAlc}$ was a strong independent predictor for risk of HCC. Our findings could be extrapolated to indicate that glycemic control could lead to a lower risk of HCC in patients with diabetes.
People with established diabetes have an increased risk of developing certain types of cancers over the general population [42-47]. Previous publications have reported the association of HCC with other comorbidities, such as diabetes mellitus [48]. In our study, Table 2 provides evidence that diabetes can increase the risk of HCC in patients with chronic liver disease. Evidence that diabetes can increase the risk of HCC was also seen in a publication written by Li et al. in 2015 [49]. Hyperinsulinemia, insulin resistance, and cytokine production have been shown to cause fat accumulation in the hepatocytes leading to oxidative stress and progressive liver injury and fibrosis [50-52]. There has also been evidence published showing a relationship between HbAlc levels, elevated liver enzymes, and hepatic steatosis [43]. Recent advances in understanding of NASH and HCC have revealed that HCC to be the leading cause of obesityrelated cancer deaths in middle aged men [53].

We conclude that HbAlc levels should only be evaluated in context with all liver function parameters as well as a red blood count in patients with liver disease. Although the pathophysiologic reasons have still not been confirmed, our data demonstrate that HbAlc levels are not a reliable predictor of glycemic control in patients with decompensated cirrhosis, especially in those with severe anemia. This interference may be due to alterations in erythrocyte lifespan and altered protein metabolism, but further investigations are needed to elucidate the exact cause of the interference in patients with liver disease.

\section{Competing Interests}

The authors declare that they have no competing interests.

\section{References}

[1] I. R. Wanless and J. S. Lentz, "Fatty liver hepatitis (steatohepatitis) and obesity: an autopsy study with analysis of risk factors," Hepatology, vol. 12, no. 5, pp. 1106-1110, 1990.

[2] Z. M. Younossi, T. Gramlich, C. A. Matteoni, N. Boparai, and A. J. McCullough, "Nonalcoholic fatty liver disease in patients with type 2 diabetes," Clinical Gastroenterology and Hepatology, vol. 2, no. 3, pp. 262-265, 2004.

[3] L. A. Adams, S. Sanderson, K. D. Lindor, and P. Angulo, "The histological course of nonalcoholic fatty liver disease: a longitudinal study of 103 patients with sequential liver biopsies," Journal of Hepatology, vol. 42, no. 1, pp. 132-138, 2005.

[4] B. R. Yehia, A. J. Schranz, C. A. Umscheid, and V. Lo Re III, "The treatment cascade for chronic hepatitis $\mathrm{C}$ virus infection in the United States: a systematic review and meta-analysis," PLoS ONE, vol. 9, no. 7, Article ID e101554, 2014.

[5] J. D. Browning, L. S. Szczepaniak, R. Dobbins et al., "Prevalence of hepatic steatosis in an urban population in the United States: impact of ethnicity," Hepatology, vol. 40, no. 6, pp. 1387-1395, 2004.

[6] M. C. Blendea, M. J. Thompson, and S. Malkani, "Diabetes and chronic liver disease: etiology and pitfalls in monitoring," Clinical Diabetes, vol. 28, no. 4, pp. 139-144, 2010.

[7] A. S. Petrides and R. A. De Fronzo, "Failure of glucagon to stimulate hepatic glycogenolysis in well-nourished patients with mild cirrhosis," Metabolism, vol. 43, no. 1, pp. 85-89, 1994. 
[8] D. García-Compean, J. O. Jaquez-Quintana, and $H$. Maldonado-Garza, "Hepatogenous diabetes. Current views of an ancient problem," Annals of Hepatology, vol. 8, no. 1, pp. 13-20, 2009.

[9] E. E. Morse, "Mechanisms of hemolysis in liver disease," Annals of Clinical and Laboratory Science, vol. 20, no. 3, pp. 169-174, 1990.

[10] W. J. Schnedl, T. Lahousen, R. Krause, S. J. Wallner, C. Piswanger-Soelkner, and R. W. Lipp, "Evaluation of conditions associated with glycated hemoglobin values below the reference range," Clinical Laboratory, vol. 53, no. 3-4, pp. 179-181, 2007.

[11] T. Lahousen, K. Hegenbarth, R. Ille et al., "Determination of glycated hemoglobin in patients with advanced liver disease," World Journal of Gastroenterology, vol. 10, no. 15, pp. 2284-2286, 2004.

[12] American Diabetes Association, "Standards of medical care in diabetes-2010," Diabetes Care, vol. 33, supplement 1, pp. S11S61, 2010.

[13] S. Maruyama, C. Hirayama, S. Yamamoto et al., "Red blood cell status in alcoholic and non-alcoholic liver disease," Journal of Laboratory and Clinical Medicine, vol. 138, no. 5, pp. 332-337, 2001.

[14] L. Cacciatore, G. Cozzolino, M. G. Giardina et al., "Abnormalities of glucose metabolism induced by liver cirrhosis and glycosylated hemoglobin levels in chronic liver disease," Diabetes Research, vol. 7, no. 4, pp. 185-188, 1988.

[15] J. C. Garcia-Pagan, A. De Gottardi, and J. Bosch, "Review article: the modern management of portal hypertension-primary and secondary prophylaxis of variceal bleeding in cirrhotic patients," Alimentary Pharmacology and Therapeutics, vol. 28, no. 2, pp. 178-186, 2008.

[16] J. G. Abraldes and J. Bosch, "The treatment of acute variceal bleeding," Journal of Clinical Gastroenterology, vol. 41, supplement 3, pp. S312-S317, 2007.

[17] D. Kravetz, "Prevention of recurrent esophageal variceal hemorrhage: review and current recommendations," Journal of Clinical Gastroenterology, vol. 41, no. 3, pp. S318-S322, 2007.

[18] R. Gonzalez-Casas, L. Garcia-Buey, E. A. Jones, J. P. Gisbert, and R. Moreno-Otero, "Systematic review: hepatitisassociated aplastic anaemia-a syndrome associated with abnormal immunological function," Alimentary Pharmacology and Therapeutics, vol. 30, no. 5, pp. 436-443, 2009.

[19] N. S. Young, R. T. Calado, and P. Scheinberg, "Current concepts in the pathophysiology and treatment of aplastic anemia," Blood, vol. 108, no. 8, pp. 2509-2519, 2006.

[20] J. K. Davies and E. C. Guinan, "An update on the management of severe idiopathic aplastic anaemia in children," British Journal of Haematology, vol. 136, no. 4, pp. 549-564, 2007.

[21] N. S. Young, P. Scheinberg, and R. T. Calado, "Aplastic anemia," Current Opinion in Hematology, vol. 15, no. 3, pp. 162-168, 2008.

[22] E. Cariani, A. M. Pelizzari, A. Rodella et al., "Immune-mediated hepatitis-associated aplastic anemia caused by the emergence of a mutant hepatitis B virus undetectable by standard assays," Journal of Hepatology, vol. 46, no. 4, pp. 743-747, 2007.

[23] J. P. Ong and Z. M. Younossi, "Managing the hematologic side effects of antiviral therapy for chronic hepatitis C: anemia, neutropenia, and thrombocytopenia," Cleveland Clinic Journal of Medicine, vol. 71, supplement 3, pp. S17-S21, 2004.

[24] N. Reau, S. J. Hadziyannis, D. Messinger, M. W. Fried, and D. M. Jensen, "Early predictors of anemia in patients with hepatitis $\mathrm{C}$ genotype 1 treated with peginterferon $\alpha$-2a (40KD) plus ribavirin," American Journal of Gastroenterology, vol. 103, no. 8, pp. 1981-1988, 2008.

[25] R. Moreno Otero and J. R. Cortés, "Nutrition and chronic alcohol abuse," Nutricion Hospitalaria, vol. 23, supplement 2, pp. 3-7, 2008.

[26] G. N. Ioannou, J. A. Dominitz, N. S. Weiss, P. J. Heagerty, and K. V. Kowdley, "The effect of alcohol consumption on the prevalence of iron overload, iron deficiency, and iron deficiency anemia," Gastroenterology, vol. 126, no. 5, pp. 1293-1301, 2004.

[27] J. Lindenbaum and M. J. Roman, "Nutritional anemia in alcoholism," The American Journal of Clinical Nutrition, vol. 33, no. 12, pp. 2727-2735, 1980.

[28] G. Laffi, F. Marra, R. Tarquini, and R. Abbate, "Coagulation defects in cirrhosis-old dogmas not yet ready for burial," Journal of Thrombosis and Haemostasis, vol. 4, no. 9, pp. 20682069, 2006.

[29] L. Bry, P. C. Chen, and D. B. Sacks, "Effects of hemoglobin variants and chemically modified derivatives on assays for glycohemoglobin," Clinical Chemistry, vol. 47, no. 2, pp. 153-163, 2001.

[30] M. I. Harris, K. M. Flegal, C. C. Cowie et al., "Prevalence of diabetes, impaired fasting glucose, and impaired glucose tolerance in U.S. adults: the Third National Health and Nutrition Examination Survey, 1988-1994," Diabetes Care, vol. 21, no. 4, pp. 518-524, 1998.

[31] M. M. Hassan, L.-Y. Hwang, C. J. Hatten et al., "Risk factors for hepatocellular carcinoma: synergism of alcohol with viral hepatitis and diabetes mellitus," Hepatology, vol. 36, no. 5, pp. 1206-1213, 2002.

[32] J.-M. Yuan, S. Govindarajan, K. Arakawa, and M. C. Yu, "Synergism of alcohol, diabetes, and viral hepatitis on the risk of hepatocellular carcinoma in blacks and whites in the U.S.," Cancer, vol. 101, no. 5, pp. 1009-1017, 2004.

[33] J. A. Davila, R. O. Morgan, Y. Shaib, K. A. McGlynn, and H. B. El-Serag, "Diabetes increases the risk of hepatocellular carcinoma in the United States: A Population Based Case Control Study," Gut, vol. 54, no. 4, pp. 533-539, 2005.

[34] T. Ohki, R. Tateishi, T. Sato et al., "Obesity is an independent risk factor for hepatocellular carcinoma development in chronic hepatitis C patients," Clinical Gastroenterology and Hepatology, vol. 6, no. 4, pp. 459-464, 2008.

[35] Y. Torisu, K. Ikeda, M. Kobayashi et al., "Diabetes mellitus increases the risk of hepatocarcinogenesis in patients with alcoholic cirrhosis: A Preliminary Report," Hepatology Research, vol. 37, no. 7, pp. 517-523, 2007.

[36] B. J. Veldt, W. Chen, E. J. Heathcote et al., "Increased risk of hepatocellular carcinoma among patients with hepatitis C cirrhosis and diabetes mellitus," Hepatology, vol. 47, no. 6, pp. 1856-1862, 2008.

[37] H. B. El-Serag, H. Hampel, and F. Javadi, "The association between diabetes and hepatocellular carcinoma: a systematic review of epidemiologic evidence," Clinical Gastroenterology and Hepatology, vol. 4, no. 3, pp. 369-380, 2006.

[38] S. A. Harrison, "Liver disease in patients with diabetes mellitus," Journal of Clinical Gastroenterology, vol. 40, no. 1, pp. 68-76, 2006.

[39] D. S. H. Bell and E. Allbright, "The multifaceted associations of hepatobiliary disease and diabetes," Endocrine Practice, vol. 13, no. 3, pp. 300-312, 2007.

[40] T. Komura, E. Mizukoshi, Y. Kita et al., "Impact of diabetes on recurrence of hepatocellular carcinoma after surgical treatment 
in patients with viral hepatitis," American Journal of Gastroenterology, vol. 102, no. 9, pp. 1939-1946, 2007.

[41] Y. Ikeda, M. Shimada, H. Hasegawa et al., "Prognosis of hepatocellular carcinoma with diabetes mellitus after hepatic resection," Hepatology, vol. 27, no. 6, pp. 1567-1571, 1998.

[42] S. Saydah, M. Tao, G. Imperatore, and E. Gregg, "GHb level and subsequent mortality among adults in the U.S.," Diabetes Care, vol. 32, no. 8, pp. 1440-1446, 2009.

[43] A. L. Christman, M. Lazo, J. M. Clark, and E. Selvin, "Low glycated hemoglobin and liver disease in the U.S. population," Diabetes Care, vol. 34, no. 12, pp. 2548-2550, 2011.

[44] H. Ma, C. Xu, L. Xu, C. Yu, M. Miao, and Y. Li, "Independent association of HbAlc and nonalcoholic fatty liver disease in an elderly Chinese population," BMC Gastroenterology, vol. 13, no. 1, article 3, 2013.

[45] X. Yang, Y. Wang, A. O. Y. Luk et al., "Enhancers and attenuators of risk associations of chronic hepatitis B virus infection with hepatocellular carcinoma in type 2 diabetes," Endocrine-Related Cancer, vol. 20, no. 2, pp. 161-171, 2013.

[46] V. Donadon, M. Balbi, F. Valent, and A. Avogaro, "Glycated hemoglobin and antidiabetic strategies as risk factors for hepatocellular carcinoma," World Journal of Gastroenterology, vol. 16, no. 24, pp. 3025-3032, 2010.

[47] X. Yang, G. T. C. Ko, W. Y. So et al., "Associations of hyperglycemia and insulin usage with the risk of cancer in type 2 diabetes: the Hong Kong diabetes registry," Diabetes, vol. 59, no. 5, pp. 1254-1260, 2010.

[48] S.-W. Lai, P.-C. Chen, K.-F. Liao, C.-H. Muo, C.-C. Lin, and F.C. Sung, "Risk of hepatocellular carcinoma in diabetic patients and risk reduction associated with anti-diabetic therapy: a population-based cohort study," The American Journal of Gastroenterology, vol. 107, no. 1, pp. 46-52, 2012.

[49] C.-I. Li, H.-J. Chen, H.-C. Lai et al., "Hyperglycemia and chronic liver diseases on risk of hepatocellular carcinoma in Chinese patients with type 2 diabetes-National cohort of Taiwan Diabetes Study," International Journal of Cancer, vol. 136, no. 11, pp. 2668-2679, 2015.

[50] S. Parekh and F. A. Anania, "Abnormal lipid and glucose metabolism in obesity: implications for nonalcoholic fatty liver disease," Gastroenterology, vol. 132, no. 6, pp. 2191-2207, 2007.

[51] G. C. Farrell and C. Z. Larter, "Nonalcoholic fatty liver disease: from steatosis to cirrhosis," Hepatology, vol. 43, no. 2, supplement 1, pp. S99-S112, 2006.

[52] X. Yang, W.-Y. So, R. C. W. Ma, A. P. S. Kong, G. Xu, and J. C. N. Chan, "Diabetes and cancer: the mechanistic implications of epidemiological analyses from the Hong Kong Diabetes Registry," Diabetes/Metabolism Research and Reviews, vol. 28, no. 5, pp. 379-387, 2012.

[53] G. A. Michelotti, M. V. Machado, and A. M. Diehl, "NAFLD, NASH and liver cancer," Nature Reviews Gastroenterology and Hepatology, vol. 10, no. 11, pp. 656-665, 2013. 


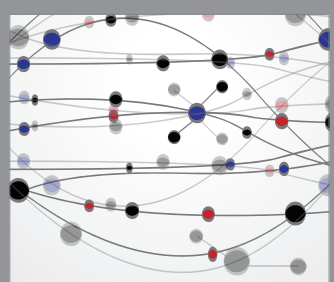

The Scientific World Journal
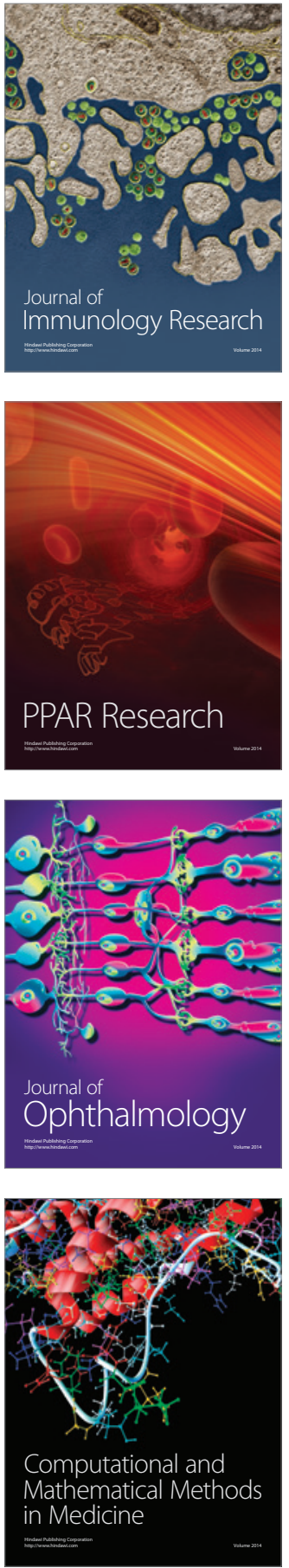

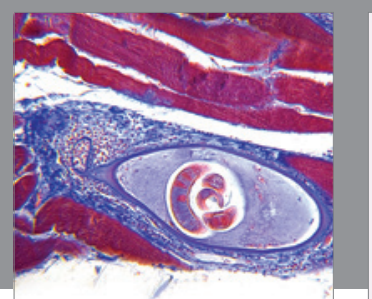

Gastroenterology Research and Practice

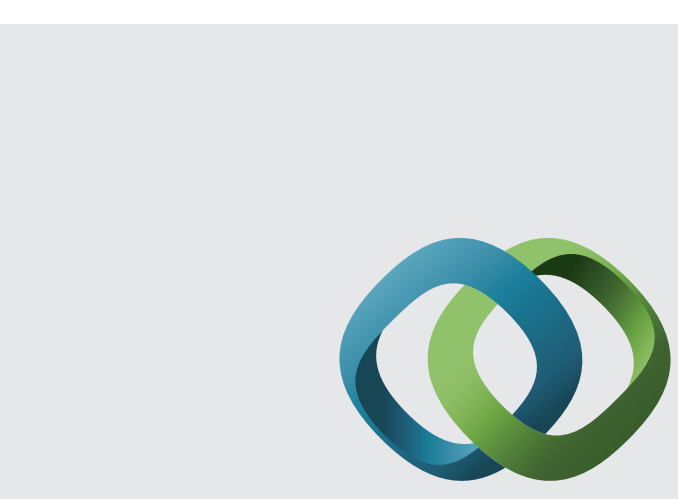

\section{Hindawi}

Submit your manuscripts at

http://www.hindawi.com
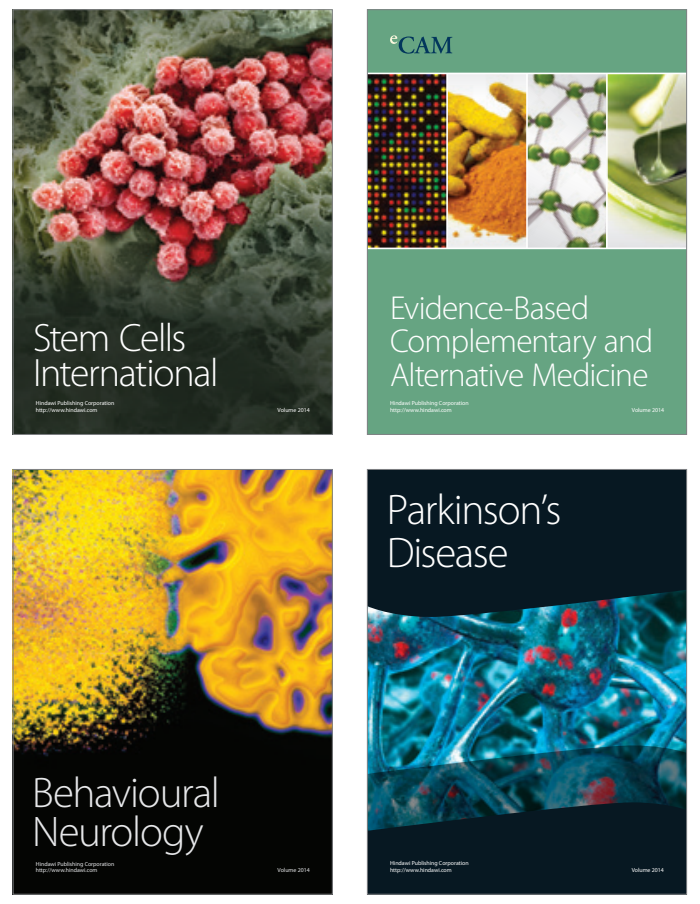
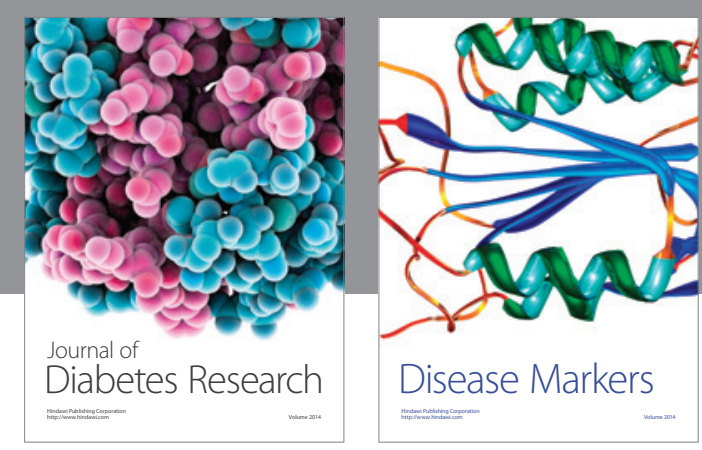

Disease Markers
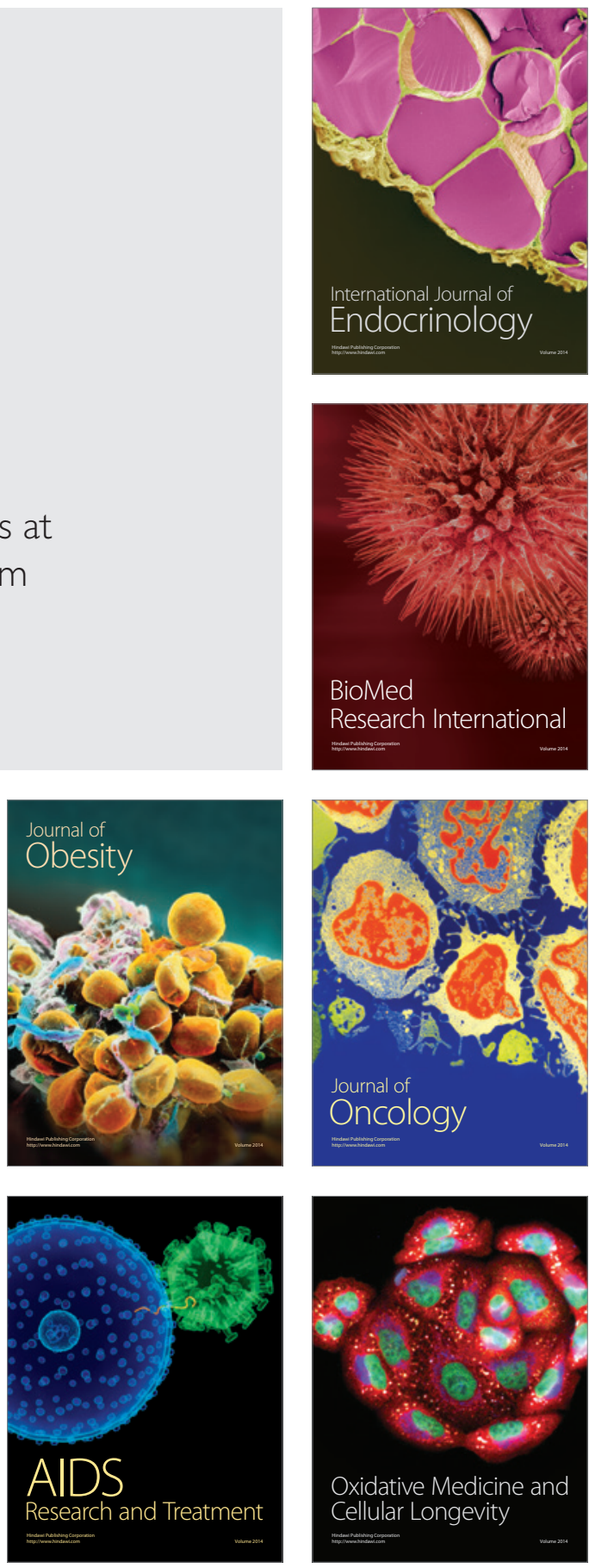